\title{
Evaluating volatile organic compounds from Chinese traditional handmade paper by SPME-GC/MS
}

\author{
Li Ding ${ }^{*}$ (D), Qin Yang, Jianhui Liu and Zheng Lee
}

\begin{abstract}
Once printed, books are always accompanied by the smells of volatile organic compounds (VOCs) which are continuously emitted not only by inks but also by papers themselves throughout their lives. Although the VOCs from papers may bring mild discomfort to readers, they are considered as very important factors that feature the degradation of papers and show potential applications in cultural relic appraisal. In this study, an analytical approach based on solid phase microextraction combined with gas chromatography-mass spectrometry (SPME-GC/MS) was proposed for the evaluation of volatile organic compounds (VOCs) emitted by Chinese traditional handmade papers. The VOCs evaluations and artificial aging processes were both applied to recent-made papers and naturally aged papers from a traditional Chinese calligraphy and painting scroll (collected by the National Museum of China). To be noticed, a large number of aliphatic acids, aldehydes, ketones, furan derivatives, benzene series and terpenoid substances indicated that the VOCs signals not only reveal the degradation of paper but also tentatively reflect the storage environment along hundreds of years ago. The semi-quantitative evaluation of markers indicated that the historical paper is under a serious degradation due to the high capacity it releases. Our results provided a path way to get the degradation information of ancient paintings as well as potential realistic applications such as the conservation of paper-based relics and the environmental protection in libraries and museums.
\end{abstract}

Keywords: SPME-GC/MS, VOCs, Handmade paper, Degradation

\section{Introduction}

Paper, since invented thousands of years ago, have been considered as the vehicle of both knowledge and history of human civilizations. Compared with rock carvings and bamboo slips, writing on papers is of more convenience with greater information storages which quickly became mainstream of the data carriers before the age of information. Since obtained from organic materials, the degradation accompanies with the papers throughout their lives as long as they are produced. It is of great importance to evaluate papers to get their ageing situations by analyzing their degradations.

*Correspondence: dingli@chnmuseum.cn

National Museum of China, No. 16 East Chang'an Avenue, Dongcheng District, Beijing 100006, People's Republic of China
Compared with modern technologies for paper evaluations which are generally destructive with the need of grams of papers. No-invasive evaluation technologies such as $\mathrm{pH}$, chromaticity, vibrational spectrometry is more acceptable in practical work especially for historical relics $[1,2]$ while these approaches can only provide either surficial information or functional group information [3-6]. Py-GC/MS (Pyrolysis gas chromatographymass spectrometry) as a possible technique involving slight invasion (several micrograms), reflects the materials composition while the pyrolysis products are usually complicated and easy to be interfered. Therefore, it is still not applicable for quantitative analysis [7-9].

Recently, the volatile organic compounds (VOCs) emitted from the paper have aroused people's concern due to its strong influences on the storage environment and

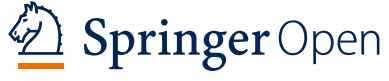

(c) The Author(s) 2021. Open Access This article is licensed under a Creative Commons Attribution 4.0 International License, which permits use, sharing, adaptation, distribution and reproduction in any medium or format, as long as you give appropriate credit to the original author(s) and the source, provide a link to the Creative Commons licence, and indicate if changes were made. The images or other third party material in this article are included in the article's Creative Commons licence, unless indicated otherwise in a credit line to the material. If material is not included in the article's Creative Commons licence and your intended use is not permitted by statutory regulation or exceeds the permitted use, you will need to obtain permission directly from the copyright holder. To view a copy of this licence, visit http://creativecommons.org/licenses/by/4.0/. The Creative Commons Public Domain Dedication waiver (http://creativeco mmons.org/publicdomain/zero/1.0/) applies to the data made available in this article, unless otherwise stated in a credit line to the data. 
the life expectancy of the paper [10-14]. VOCs emitted from paper are the main odor source in the libraries and archives, and are recognized as a natural ageing feature of the papers. Matija Strlič proposed paper metabolomics theory, which described that the ageing behavior of paper is analogous to the metabolic behavior of organisms. The VOCs are metabolites which help others learn about the degradation behaviors $[1,12,14,15]$. At the same time, the VOCs will accelerate the degradation of papers, which may in turn become the VOC absorbers [12].

Solid phase microextraction (SPME) combined with gas chromatography-mass spectrometry (GC/MS) is an effective no-invasive method for the collection, separation and detection of volatile organic compounds (VOCs) emitted by papers [12, 16-22]. Previous studies showed the SPME fiber with selected filler collected the aliphatic acid, aldehyde and furfural from natural and artificial aged wood pulp. Different VOCs were verified to be the degradation products of cellulose and lignin [12, 23-25]. With the help of this method, papers made from various materials including cotton/linen [25], wood pulp [25, 26], raw fibers [27] and even moldy paper with microorganisms $[19,28]$ have been intensively studied with applausive results in early European and Arab traditional papermaking technology. However, to our knowledge, VOCs emitted from Chinese traditional handmade papers is still unexplored.

The origin of Chinese handmade paper can be traced back to 2000 years ago, and it was the principal carrier for culture to spread and inherit. A large number of paper-based heritages are preserved due to the high mechanical property and high stability of the traditional handmade paper, such as the ancient book The Records of the Three Kingdoms and the earliest Chinese calligraphy Pingfu Post from the third century. The historical restoration is another critical factor to increase the lifetime expectancy of the paper in the past or present. Chinese handmade paper is widely applied to the conservation on paper-based heritage artifacts.

In this work, SPME-GC/MS was applied to evaluate the volatile organic compounds (VOCs) emitted from three kinds of Chinese traditional handmade paper and a common mechanical newspaper. Our research aims to establish a list of VOCs from Chinese handmade papers as well as sorting out the degradation marker molecules. The SPME-GC/MS proved its practical applications in historical paper examination, the evaluation of the natural degradation papers which may further extend our understandings of no-invasive characterization of cultural relics.

\section{Materials}

\section{Reference paper}

Handmade papers were purchased from three different provinces in China, which boast famous producers of traditional Chinese handmade papers. The mechanical papers were selected as references in the control experiments. The information of the paper samples was listed in Table 1.

\section{Agarwood and Mixiang paper}

Vietnam agarwood was purchased from Aijia collection, Beijing.

\section{Historical paper}

Jiang Youzhu et al. seven digging mounted painting scroll is a traditional Chinese calligraphy and painting scroll from the Qing Dynasty (C.E 1636-1912) collected by the National Museum of China. The whole scroll can be divided into three parts: the upper part, the middle part and the lower part. P1 is a running script, signed by Chen Liangzhen ( 陈良筬), who was a calligrapher from Fujian province. P2 has no inscription. P3 is a painting which was inscribed by Jiang Youzhu (江友渚), who was a painter from the central Fujian province of the Qing Dynasty [29]. P4 has no inscription. P5 is the seal character which was contributed by Fan Can (范燦). P6 and P7 were scribed by Hong Ji (洪 基), who was a folk artist from Fujian province [29]. According to the time documented, the “甲申菊秋” and “甲申小 春" in P6 and P7, which hinted that the painting might be finished in C.E 1644, 1704 or 1764. Since the dates of birth and death of artists were not documented, the age of scroll

Table 1 Summary of the samples of known origins used in the course of the present studies

\begin{tabular}{|c|c|c|c|c|c|c|}
\hline Product Name & Common name & Catalogue & Fiber origin & Year & Place & $\begin{array}{l}\text { Paper } \\
\text { grammage } \\
\left(\mathrm{g} / \mathrm{m}^{2}\right)\end{array}$ \\
\hline Gaoli & Mulberry paper & Handmade & Morus alba & 2015 & Qian'an, Hebei & 29.2 \\
\hline Yukouzhi & Bamboo paper & Handmade & Phyllostachys pubescens & 2011 & Ninhua, Fujian & 37.1 \\
\hline Xuan & Rice paper & Handmade & $\begin{array}{l}\text { Pteroceltis tatarinowii Maxim } \\
\text { and Oryza sativa }\end{array}$ & 2017 & Jingxian, Anhu & 23.8 \\
\hline Wood pulp & Wood pulp paper & Mechanical & Wood pulp & 2000 & - & 46.0 \\
\hline
\end{tabular}


could not be clearly verified. The content of the running script and seal character were compliments to the generals of central Fujian province. In addition to the “奉祝请正” in the running script, the aim of the creation was to offer birthday congratulations to a general. The scroll was digging mounted with papers and badly damaged with stains and cracks around the mounting materials. The conservator decided to remount the scroll to extend the life of calligraphies and paintings. The substituted wrecked head margin paper was collected and further studied by SPME-GC/MS.

\section{Experiments and methods}

\section{Artificial ageing}

$200 \mathrm{mg}$ or $150 \mathrm{mg}$ of reference paper sample was put into a $20 \mathrm{~mL}$ headspace bottle. 5 groups of papers were prepared, among which 1 group was taken as a control. The other 4 groups of samples underwent 1,2,3,4 ageing cycles, respectively. Each ageing cycle was $72 \mathrm{~h}$. Three parallel samples were prepared for each group. The temperature and the humidity were controlled by the constant temperature humidity chamber following standard ISO 5630-3:1996. The ageing temperature was $80^{\circ} \mathrm{C}$ and the relative humidity was $65 \%$. Light was avoided inside the chamber. The brand and model of the constant temperature humidity chamber used is KBF-115 (Binder, Germany). The total ageing time was listed in Table 2. Historical paper at sampling location 5 (Fig. 1) were manipulated under the same artificial ageing process. The photographs and mass records of reference sample and historical paper were attached in Additional file 1: Figure S1 and Table S1.

\section{Paper fiber observation}

Paper samples were stained with Graff "C" reagent to assess the presence of color and morphology of fiber. The paper samples were observed under the Leica Dmrxa2 microscope.

The scanning electron microscope images of paper fibers were obtained via FEI Quanta 650.

\section{SPME-GC/MS}

The VOCs emitted by reference papers $(200 \mathrm{mg} / 150 \mathrm{mg})$ at different ageing stages and historical paper $(200 \mathrm{mg})$ were collected by solid phase microextraction fiber. The SPME extraction was performed automatically on each aged sample in the headspace bottle using $120 \mu \mathrm{m}$ ARR11-DVB/ CWR120/20 (Divinylbenzen-Carboxen/Poly (Dimethylsiloxane), SPME arrow fiber. The filler is suitable for a wide

Table 2 Total ageing time for different ageing stage

\begin{tabular}{llllll}
\hline Ageing stage & Fresh & Cycle 1 & Cycle 2 & Cycle 3 & Cycle 4 \\
\hline Ageing total time (h) & 0 & 72 & 144 & 216 & 288 \\
\hline
\end{tabular}

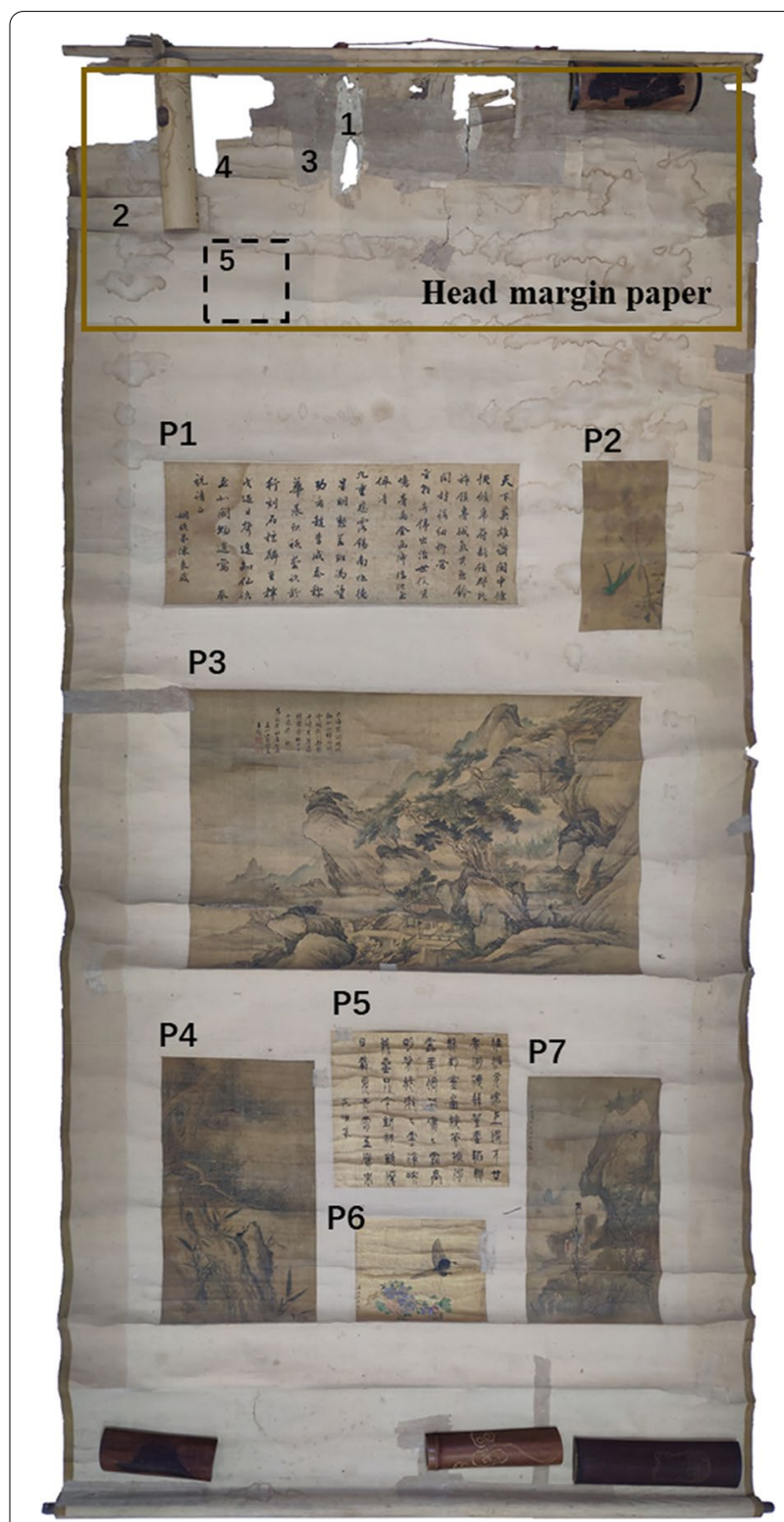

Fig. 1 The photograph of "Jiang Youzhu et al. seven digging mounted painting scroll". The location of samples for SPME-GC/MS and fiber observation was labeled

range of chemicals and was successfully used for studies on paper-based materials [25]. The extraction was performed according to the adapted methods available in literatures $[23,26,30,31]$. The fiber was pre-conditioned in the GC injection port at $230{ }^{\circ} \mathrm{C}$ for 3 min before extraction. Then the vial with paper sample was placed in the incubation block at $60{ }^{\circ} \mathrm{C}$ for $30 \mathrm{~min}$. The fiber was inserted into the vial at a depth of $32 \mathrm{~mm}$ to extract the analyst for $30 \mathrm{~min}$ at $60{ }^{\circ} \mathrm{C}$. After that, the analyte was then immediately desorbed by insertion of the fiber into the injector port of chromatograph at a depth of $45 \mathrm{~mm}$ for $5 \mathrm{~min}$ at $230^{\circ} \mathrm{C}$. All 
the above processes were completed on three-in-one automatic pretreatment platform (Zhida, Guangzhou). In addition, an empty vial without a paper sample was also tested as a blank.

The volatile compounds were identified by gas chromatography-mass spectrometry (GC/MS) analysis with a 7890A-5975C (Agilent, USA). The chromatograph was equipped with a DB-5MS capillary column, $30 \mathrm{~m} \times 0.25 \mathrm{~mm}, 0.25 \mu \mathrm{m}$ film thickness. The temperature of chromatographic elution was programmed as follows: isothermal at $35{ }^{\circ} \mathrm{C}$ for $10 \mathrm{~min}$, then from $35-250{ }^{\circ} \mathrm{C}$ at a rate of $5{ }^{\circ} \mathrm{C} / \mathrm{min}$, and isothermal hold at $250{ }^{\circ} \mathrm{C}$ for $30 \mathrm{~min}$. The split/splitless injector was used in splitless mode and its temperature was maintained at $230{ }^{\circ} \mathrm{C}$. The interface temperature was set at $270{ }^{\circ} \mathrm{C}$. Mass spectra were acquired under electron ionization mode (EI) at $70 \mathrm{eV}$ and recorded from $\mathrm{m} / \mathrm{z} 33-700 \mathrm{amu}$. TIC mode was used for peak analysis of the total ion current spectrum, and the peak with $\mathrm{S} / \mathrm{N}$ above 3 was extracted and compared with the NIST 2014 spectrum library.

For targeted monitoring and semi-qualitative measurement, the chromatograph was equipped with a HPINNOWax capillary column, $30 \mathrm{~m} \times 0.25 \mathrm{~mm}, 0.25 \mu \mathrm{m}$ film thickness. The temperature of chromatographic elution was programmed as follows: isothermal at $50{ }^{\circ} \mathrm{C}$ for 2 min, then from 50 to $240{ }^{\circ} \mathrm{C}$ at a rate of $10{ }^{\circ} \mathrm{C} / \mathrm{min}$, and isothermal hold at $240{ }^{\circ} \mathrm{C}$ for $2 \mathrm{~min}$. The split/splitless injector was used in splitless mode and its temperature was maintained at $230{ }^{\circ} \mathrm{C}$, while the interface temperature was set at $260^{\circ} \mathrm{C}$. Mass spectra were acquired under electron ionization mode (EI) at $70 \mathrm{eV}$ and recorded from $\mathrm{m} / \mathrm{z}$ 15-300 amu. Deconvolution mode was used for peak analysis of the total ion current spectrum.

\section{External standard}

$10,20,30,40,50,50,60,70,80,90,100\left(10^{-6} \mathrm{~g} / \mathrm{mL}\right)$ of Acetic acid in methanol were prepared to obtain the linear calibration curves. The GC/MS injection volume of external standard was $0.5 \mu$ l.

\section{Semi-quantitative calculation}

In this study, the trend of VOC emission was evaluated semi-quantitatively by dealing with the analyte absorbed by the SPME arrow fiber. The amount of analyte extracted onto the coating is linearly proportional to the analyte concentration in the bottle [32].

The semi-quantitative calculation was as follows:

$$
C_{R}\left(\frac{n g}{g} \text { paper }\right)=\frac{M_{f}}{M_{P}}=\frac{C_{0}\left(10^{-6} g / m L\right) \times 0.5(\mu L)}{M_{P}(\text { g paper })}
$$

$M_{f}$ is the mass of adsorbed substance on the SPME arrow fiber. $M_{p}$ is the mass of the paper. $C_{0}$ is the calibrated concentration. $C_{R}$ is the emission rate of targeted compounds. The diameter of SPME arrow fiber was $1.5 \mathrm{~mm}$. The DI liner tube with inner diameter with $2 \mathrm{~mm}$ was applied to ensure the injection efficiency of SPME and liquid injection was near 95\% [33]. $M_{f}$ is the mass of adsorbed substance on the SPME arrow fiber.

\section{Results and discussion Morphologies of fibers}

As shown in Fig. 2a, Mulberry paper is composed of mulberry bark fiber and Eulens binata fiber. The mulberry bark fiber turns wine red after being dyed with Graff " $C$ " reagent. The fiber is cylindrical with smooth surface and oblique transverse node stripes. Amorphous wax attached to the fiber wall can be observed. As shown in Fig. 2b, the Bamboo paper is composed of bamboo fibers, which are characterized by tapering of the fiber ends and reticulated vessel element. As shown in Fig. 2c, Rice paper consists of a small amount of bark and straw. Straw fiber at both ends is tiniest and with transverse section lines on the cell wall. In addition, the serrated epidermal cells of the straw were shown in the Figure inserted. As shown in Fig. 2d, the Wood pulp paper is made of mechanical softwood groundwood paper pulp, since the Graff "C" stain creates a vivid yellow color. It is basically consistent with the information of labels of the products. The SEM images of fibers were also shown in Additional file 1: Figure $S 2$.

\section{Non targeted screening of VOCs}

Solid-phase micro-extraction was carried out following a non-invasive analytical method previously proposed for the determination of VOCs in paper samples [23, 26, 30, 31]. The SPME fiber with Divinylbenzen-Carboxen/Poly (Dimethylsiloxane) fillers were tested to be suitable for absorbing a wide range of VOCs from the paper materials $[25,26]$. In this work, the arrow SPME fiber with the same filler was applied. Owing to the larger adsorption surface area, the arrow SPME fiber could achieve higher extraction efficiency. In Fig. 3, the typical chromatograms obtained in Mulberry, Bamboo, Rice and Wood pulp paper were reported. The peak identification was performed by the corresponding mass spectra compared with the NIST2014 database. 87 compounds were clearly identified (Table 3) compared with a blank chromatogram, where these compounds were not detected.

Peaks labeled with asterisks in Fig. 3 were identified to be derivatives of siloxane as contaminants which are likely derived from SPME fibers. These 87 compounds comprise the aliphatic acid, aldehyde, ketone, alkane, furan derivative and benzene series. The aliphatic acids, like acetic acid, propanoic acid, butanoic acid and pentanoic acid, are notorious for acidification of paper [13, 

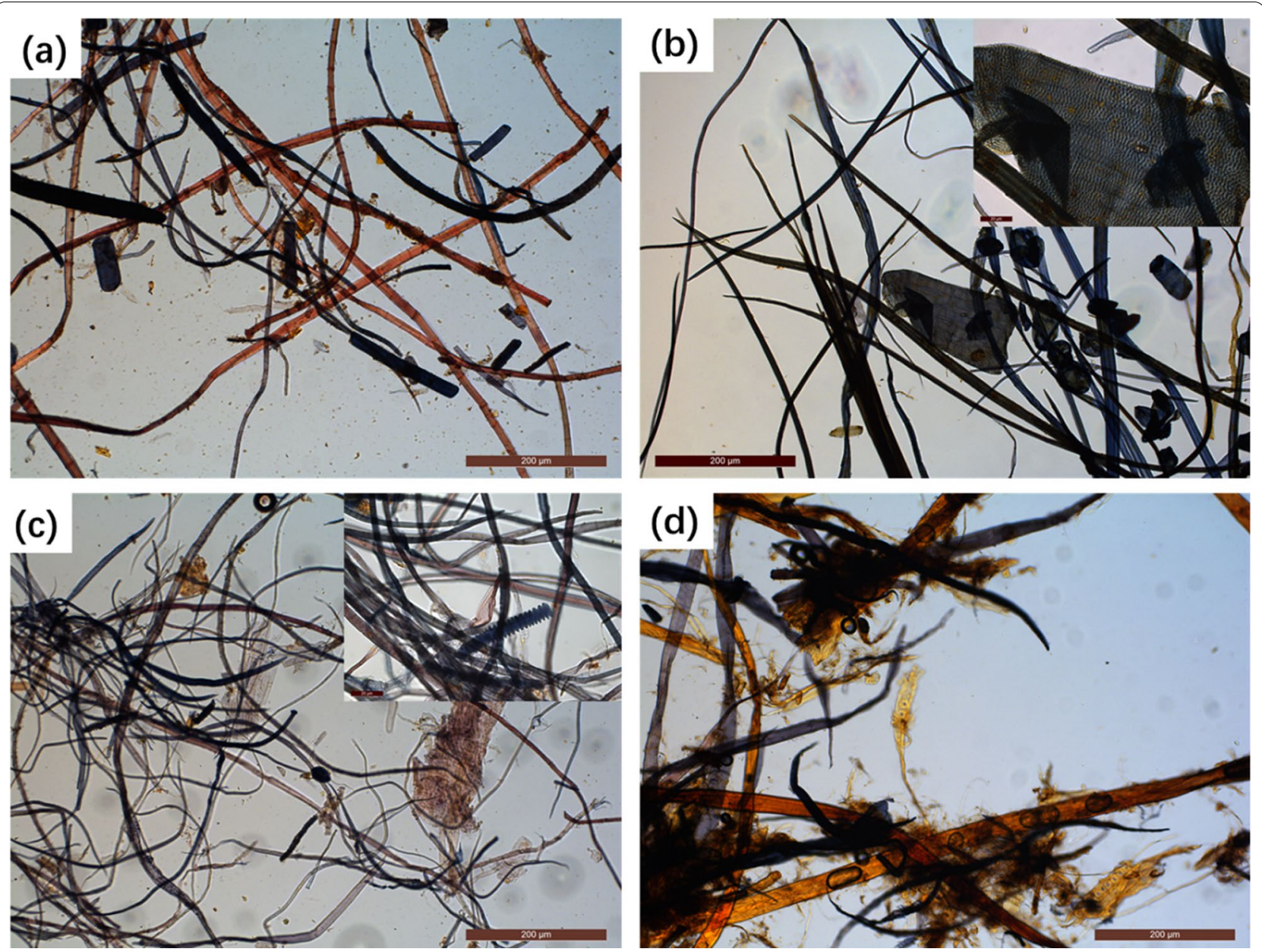

Fig. 2 The optical microscopy images of the fiber from a Mulberry paper, b Bamboo paper, c Rice paper and $\mathbf{d}$ Wood pulp paper

30]. These short chain acids could be emitted from various degradation of the paper, such as the deep degradation of cellulose and oxidation of lipid [2,30]. However, several long chain aliphatic acids $\left(C_{n}>10\right)$ were also detected in our studies. For instance, $\mathrm{C}_{14}$ and $\mathrm{C}_{16}$ were found in the Bamboo paper which is made from Phyllostachys pubescens fibers. The straight chain aldehyde $\left(\mathrm{C}_{6}-\mathrm{C}_{18}\right)$ and Ketone $\left(\mathrm{C}_{7}-\mathrm{C}_{15}\right)$ identified in the samples are convenient markers for the autoxidation of aliphatic acids, which naturally exist as residual resins known to be dominated by the 18 carbon unsaturated acids oleic, linoleic and linolenic acids [24,30]. Alkane mainly originated from waxy residue on the surface of fibers or degradation of lipid and unsaturated hydroperoxides [30, 34-36]. Furan derivatives are typical products of degradation due to the acid hydrolysis of five- to six-carbon sugar in cellulose and hemicellulose. The representative compound was furfural. Besides, 2-Furanmethanol, 2-pentyl-Furan, 5-ethyldihydro-5-methyl-2(3H)-Furanone, 5-ethyldihydro-5-methyl-2(3H)-Furanone and dihydro-5-pentyl- 2(3H)-Furanone were also detected. Monomethoxylated phenolic compounds (such as vanillin, guaiacol or other benzene series) with a smoky aroma arising from lignin degradation can be considered as a degradation compound of groundwood pulp paper [23]. In this investigation, vanillin and guaiacol were prominently screened out in Bamboo and Wood pulp paper. It might be due to the high concentration of lignin in the Phyllostachys pubescens fibers and wood pulp. In addition, some plant markers were identified. For instance, the cedrene was unique to be found in the Rice paper, which indicated that the essential oil might be the additive. The camphor was found in the Mulberry, Rice and Wood pulp paper, which might be due to the additive of camphor for expelling parasites. However, until further verification, these are only speculations. The environmental contaminations would contribute as well. Therefore, the evaluation of VOCs from papers could not only give the information of the degradation but also help with looking into manufacturing technology or the storage 


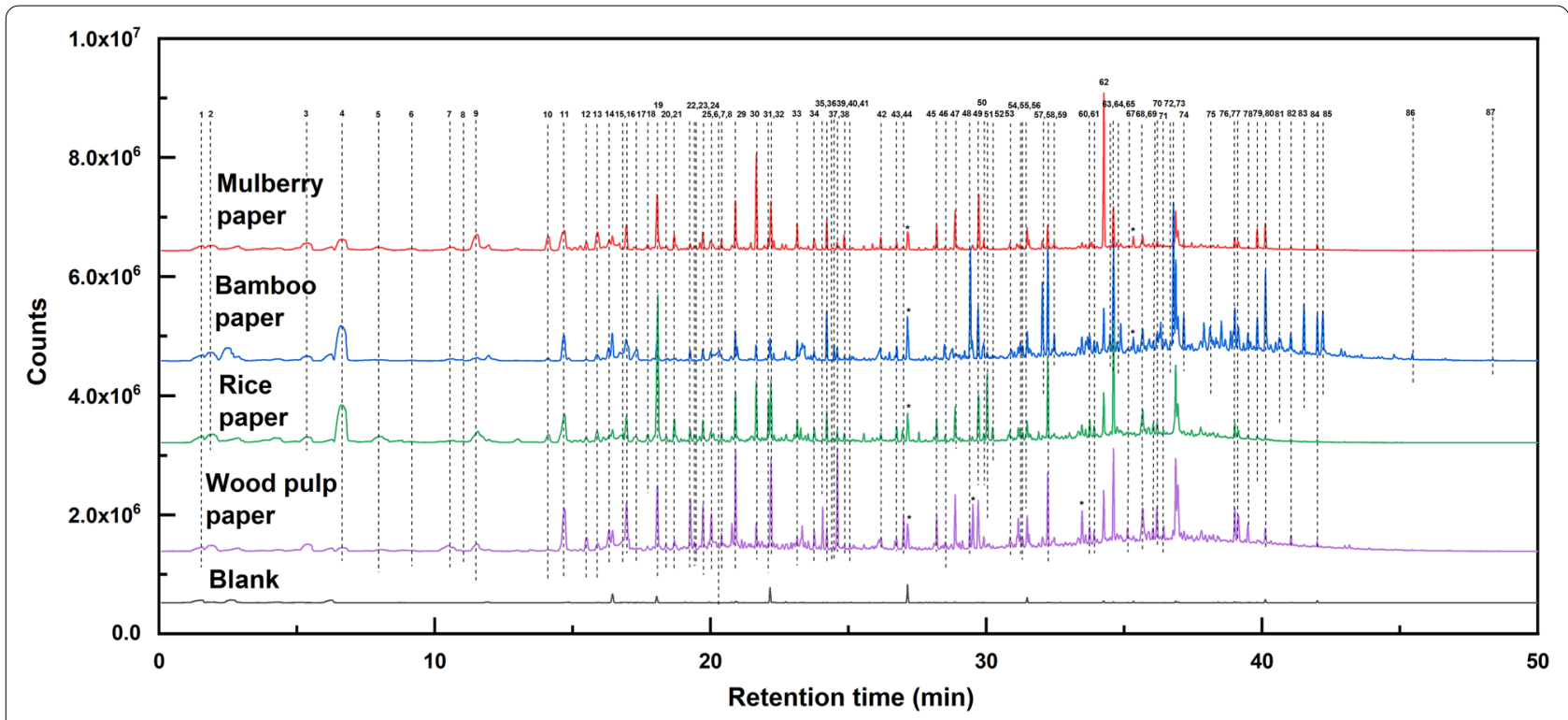

Fig. 3 Total ion current chromatograms obtained from SPME-GC/MS of Mulberry, Bamboo, Rice and Wood pulp paper. The empty vial was measured as a blank reference

environment during the past years. The VOCs emitted from paper and their corresponding sources are listed in Table 4.

\section{Monitoring of artificial ageing process}

The VOCs related to the degradation were selected to monitor the artificial ageing process of paper. Typically, aliphatic acids, furan derivatives, aldehyde and ketone were surveyed independently. In order to evaluate the products of degradation semi-quantitatively, the PEG (polyethylene glycol) column with strong polarity was employed. The peak patterns of acids, furan derivatives and aldehyde were improved as shown in Additional file 1: Fig. S4. The amount of absorbed substance on the SPME fiber $\left(\mathrm{M}_{\mathrm{f}}\right)$ was calculated by the external standard curve and further calibrated on the paper mass $\left(C_{R}\right)$. Even though the response factors of targeted compounds are various, this result clearly showed the applicability of SPME for identifying and semi-quantifying VOCs emitted from paper, the original data were supplied in Additional file 2 .

As shown in Fig. 4, the continuous growth of VOCs from Mulberry paper was observed as more artificial ageing cycles were applied. To be mentioned, not all the compounds were ideally suited for indicating the ageing progress of paper. In Fig. 4a the content of most acids kept increasing with ageing. Typically, the concentration of acetic acid and hexanoic acid is 12.7 and $15.1 \mathrm{ng} / \mathrm{g}$ at cycle 4, respectively. The concentration of 2-ethylHexanoic acid showed a decline in Cycle 4, which is not proper to be an indicator. As for furan derivatives, furfural was known as an important degradation marker for paper and its accumulation was clearly monitored by the SPME-GC/MS as shown in Fig. 4b. The concentration of furfural is $33.8 \mathrm{ng} / \mathrm{g}$ at cycle 4 . Accumulation of other furan derivatives was relatively slow. In Fig. 4c, straight chain aldehyde $\left(\mathrm{C}_{9}-\mathrm{C}_{10}\right)$ experienced a consumption during the ageing, which might be due to the limitation degradation of the unsaturated acid. However, octanal showed conspicuous formation after the first ageing cycle and increased until Cycle 4. Abundant ketone compounds were detected (including $\mathrm{C}_{8}-\mathrm{C}_{15}$ ), whose contents went through a slight increment. As shown in Fig. $4 \mathrm{~d}$, benzene series such benzaldehyde, acetophenone are highly relative to the degradation of lignin. Since benzaldehyde comprehensively exists in the plant stems and leaves in the form of glycoside, it is not surprising to find them in the Mulberry paper. As the degradation proceeds, the benzaldehyde continues to be sent out, which might account for the hydrolysis of its glycoside, such as amygdalin [37, 38]. In conclusion, for Mulberry paper, acetic acid and hexanoic acid, furfural and benzaldehyde were demonstrated to be the degradation molecular markers.

Bamboo paper has emerged since the Song Dynasty (C.E 960-1279). Compared with other handmade papers, Bamboo paper usually has poor anti-ageing performance. As shown in Fig. 5a acetic acid and hexanoic acid as the most important degradation markers increased remarkably during ageing. The concentrations of acetic acid and 
Table 3 The assignment of VOCs detected from the Mulberry, Bamboo, Rice and Wood pulp paper

\begin{tabular}{|c|c|c|c|c|c|c|c|}
\hline No & $t_{R} / \min$ & Assignment & Score & No & $t_{R} / \min$ & Assignment & Score \\
\hline 1 & 1.60 & 2-Propanamine & 78 & 45 & 28.12 & 2,2,4-Trimethyl-1,3-pentanediol diisobutyrate & 89 \\
\hline 2 & 1.87 & Acetic acid & 76 & 46 & 28.50 & dihydro-5-pentyl-2(3H)-Furanone & 93 \\
\hline 3 & 5.37 & Hexanal & 96 & 47 & 28.85 & $\begin{array}{l}\text { Propanoic acid, 2-methyl-, 3-hydroxy-2,2,4-trimethylpentyl } \\
\text { ester }\end{array}$ & 98 \\
\hline 4 & 6.59 & Furfural & 99 & 48 & 29.39 & Vanillin & 98 \\
\hline 5 & 8.01 & 2-Furanmethanol & 86 & 49 & 29.71 & 6,10-dimethyl-2-Undecanone & 97 \\
\hline 6 & 9.09 & 1-Hexanol & 91 & 50 & 29.89 & Dodecanal & 97 \\
\hline 7 & 10.60 & 2-Heptanone & 82 & 51 & 30.02 & a-Cedrene & 97 \\
\hline 8 & 11.00 & Pentanoic acid & 70 & 52 & 30.22 & $\beta$-Cedrene & 94 \\
\hline 9 & 11.51 & Heptanal & 97 & 53 & 30.85 & Geranyl acetone & 94 \\
\hline 10 & 14.12 & 3-Ethyl-4-methylpentan-1-ol & 91 & 54 & 31.21 & 2,6,10-Trimethyltridecane & 91 \\
\hline 11 & 14.68 & Benzaldehyde & 97 & 55 & 31.32 & 2-methyl-Tetradecane & 87 \\
\hline 12 & 15.49 & 1-Heptanol & 94 & 56 & 31.55 & Cyclododecane & 91 \\
\hline 13 & 15.89 & Phenol & 89 & 57 & 32.03 & 1-Pentadecene & 98 \\
\hline 14 & 16.30 & 2-pentyl-Furan & 89 & 58 & 32.22 & Pentadecane & 98 \\
\hline 15 & 16.83 & Hexanoic acid & 91 & 59 & 32.47 & Tetradecanal & 85 \\
\hline 16 & 16.94 & Octanal & 97 & 60 & 33.74 & 2-methyl-Pentadecane & 90 \\
\hline 17 & 17.23 & 1H-Pyrrole-2-carboxaldehyde & 95 & 61 & 33.90 & 3-methyl-Pentadecane, & 85 \\
\hline 18 & 17.71 & 5-ethyldihydro-5-methyl-2(3H)-Furanone & 86 & 62 & 34.25 & 2,2,4-Trimethyl-1,3-pentanediol diisobutyrate & 98 \\
\hline 19 & 18.05 & 2-ethyl-1-Hexanol & 98 & 63 & 34.48 & 2-Tetradecanone & 86 \\
\hline 20 & 18.37 & 2-hydroxy-Benzaldehyde, & 79 & 64 & 34.60 & Hexadecane & 98 \\
\hline 21 & 18.67 & 4,6-dimethyl-2-Heptanone & 86 & 65 & 34.73 & Cedrol & 90 \\
\hline 22 & 19.25 & Acetophenone & 87 & 66 & 35.12 & Benzophenone & 89 \\
\hline 23 & 19.39 & 4-methyl-Benzaldehyde & 95 & 67 & 35.67 & 2,6,10-trimethyl-Pentadecane & 90 \\
\hline 24 & 19.46 & 2-Acetonylcyclopentanone & 82 & 68 & 36.04 & 2-methyl-Hexadecane & 88 \\
\hline 25 & 19.71 & 1-Octanol & 99 & 69 & 36.18 & 2,2',5,5'-tetramethyl-1,1'-Biphenyl & 90 \\
\hline 26 & 20.02 & Guaiacol & 92 & 70 & 36.42 & 3,4-diethyl- 1,1'-Biphenyl, & 85 \\
\hline 27 & 20.32 & Heptanoic acid & 74 & 71 & 36.69 & E-15-Heptadecenal & 82 \\
\hline 28 & 20.39 & 2-Nonanone & 91 & 72 & 36.77 & 2-Pentadecanone & 96 \\
\hline 29 & 20.89 & Nonanal & 99 & 73 & 36.86 & Heptadecane & 91 \\
\hline 30 & 21.64 & 1-methyl-4-(1-methylethyl)-,cis-Cyclohexanol & 85 & 74 & 37.15 & Pentadecanal & 92 \\
\hline 31 & 22.08 & (R,S)-5-Ethyl-6-methyl-3E-hepten-2-one & 98 & 75 & 38.10 & Tetradecanoic acid & 91 \\
\hline 32 & 22.18 & Camphor & 98 & 76 & 38.99 & Octadecane & 94 \\
\hline 33 & 23.13 & 1-Nonanol & 95 & 77 & 39.12 & 2,6,10,14-tetramethyl-Hexadecane & 92 \\
\hline 34 & 23.75 & 2-Decanone & 87 & 78 & 39.47 & Isopropyl myristate & 93 \\
\hline 35 & 24.06 & Dodecane & 98 & 79 & 39.81 & 6,10,14-trimethyl-2-Pentadecanone & 96 \\
\hline 36 & 24.21 & Decanal & 99 & 80 & 40.12 & 1,2-Benzenedicarboxylic acid, bis(2-methylpropyl) ester & 96 \\
\hline 37 & 24.41 & 2-propyl-1-Heptanol & 85 & 81 & 40.62 & n-Nonadecanol-1 & 86 \\
\hline 38 & 24.47 & 2,3-dihydro-Benzofuran & 93 & 82 & 40.89 & 4-Octadecenal & 62 \\
\hline 39 & 24.58 & Benzothiazole & 94 & 83 & 41.51 & Hexadecanoic acid, methyl ester & 98 \\
\hline 40 & 24.84 & Undecanal & 88 & 84 & 42.00 & Dibutyl phthalate & 95 \\
\hline 41 & 25.04 & Isophthalaldehyde & 92 & 85 & 42.20 & n-Hexadecanoic acid & 97 \\
\hline 42 & 26.02 & Nonanoic acid & 95 & 86 & 45.45 & (Z)-18-Octadec-9-enolide & 89 \\
\hline 43 & 26.74 & 2-Undecanone & 97 & 87 & 48.36 & 10-methyl-Eicosane & 79 \\
\hline 44 & 26.99 & Tridecane & 97 & & & & \\
\hline
\end{tabular}

hexanoic acid are 14.6 and $15.1 \mathrm{ng} / \mathrm{g}$ at cycle 4 , respectively. In addition, the amount of other acids gradually increased as well. With regard to furfural, it maintained a stable rising tendency as expected (Fig. 5b). The concentration of furfural is $12.5 \mathrm{ng} / \mathrm{g}$ at Cycle 4 . The variations of aliphatic aldehyde and ketone were complicated 
Table 4 The VOCs emitted from paper and their corresponding sources

\begin{tabular}{|c|c|}
\hline Source & VOCs \\
\hline $\begin{array}{l}\text { Cellulose and Hemicel- } \\
\text { lulose }\end{array}$ & Furan derivatives, short chain aliphatic acids \\
\hline Lignin & Vanillin, guaiacol, benzene series \\
\hline Lipid & Straight chain aldehyde Ketone, Alkane \\
\hline Wax & Alkane \\
\hline Plant markers & Camphor, Cedrene \\
\hline
\end{tabular}

for the Bamboo paper. As shown in Fig. 5c, aliphatic aldehyde $\left(\mathrm{C}_{7}-\mathrm{C}_{9}\right)$ showed freshly high content and experienced a decline during the ageing. ketone compounds ranging from $\mathrm{C}_{8}$ to $\mathrm{C}_{13}$ were detected and the content of them went through a slight increase. As for emission rate of benzene series in Fig. 5d, Bamboo paper showed relative high level. It is $9.8 \mathrm{ng} / \mathrm{g}$ for benzaldehyde at cycle
4, which hints a high lignin content of Bamboo paper. Hence for Bamboo paper, acetic acid and hexanoic acid, furfural and benzaldehyde were demonstrated to be the degradation molecular markers.

Rice paper, mostly made of mixed Pteroceltis tatarinowii Maxim and Oryza sativa, are produced from Jingxian, Anhui, and considered as the most famous paper for mounting and repairing traditional Chinese painting and calligraphy. In Fig. $6 a$ the amount of aliphatic acid, such as acetic acid, hexanoic acid increase as the degradation progress, which is similar to the Mulberry and Bamboo paper. The concentrations for acetic acid and hexanoic acid are 12.1 and $11.4 \mathrm{ng} / \mathrm{g}$ at cycle 4 , respectively. It is shown in Fig. 6b, furfural maintained a stable rising tendency and the emission rate was up to $68.9 \mathrm{ng} / \mathrm{g}$, which demonstrated the high furfural release capacity of Rice paper. Concerning the aldehyde and ketone compounds, as shown in Fig. 6c, a relative high concentration of aliphatic aldehyde with $\mathrm{C}_{7}, \mathrm{C}_{9}, \mathrm{C}_{10}, \mathrm{C}_{11}$ was detected
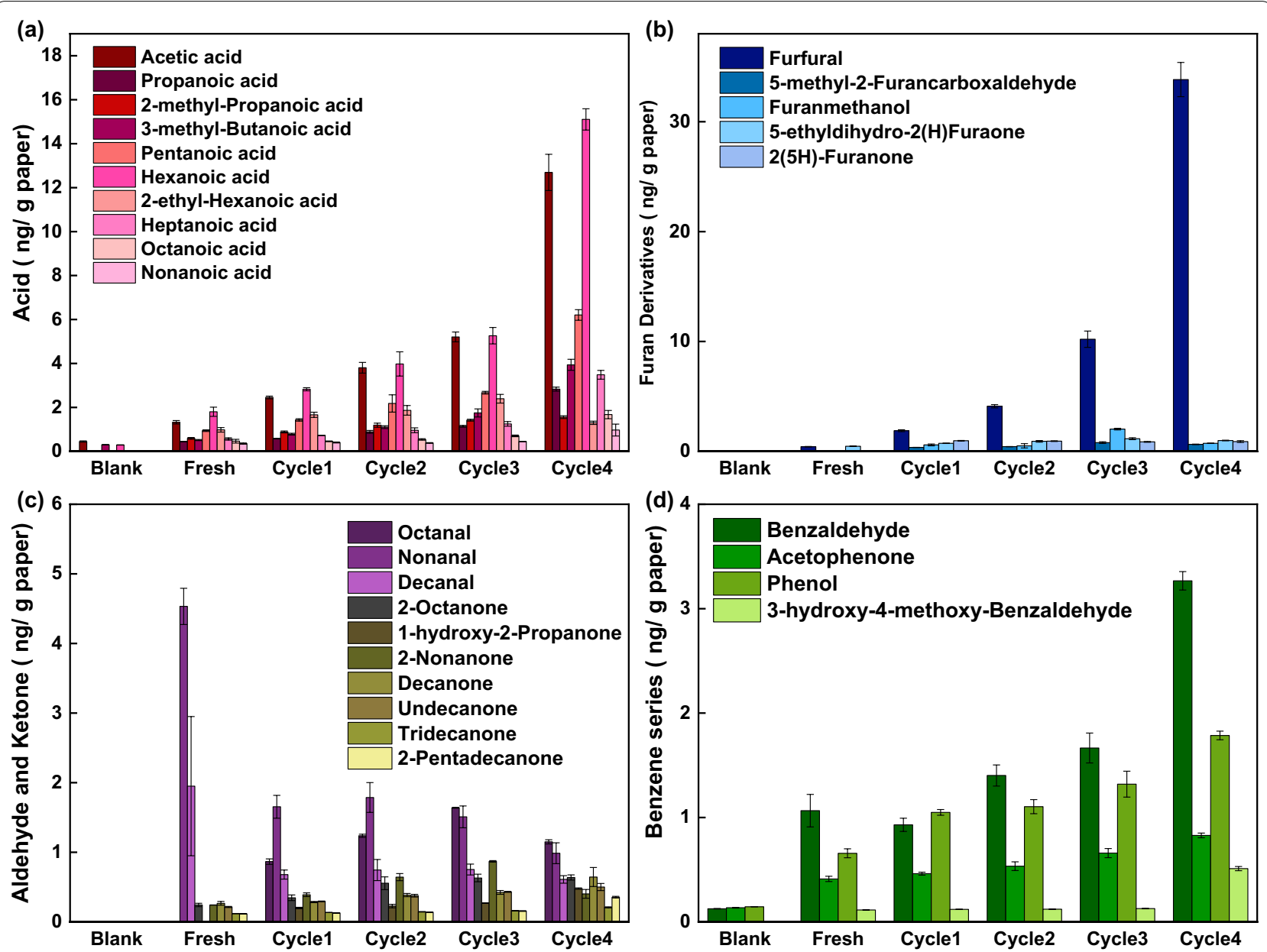

Fig. 4 a The emission rate of aliphatic acid $\mathbf{b}$ Furfural derivatives $\mathbf{c}$ aliphatic aldehyde and ketone $\mathbf{d}$ benzene series in different ageing stage for Mulberry paper 

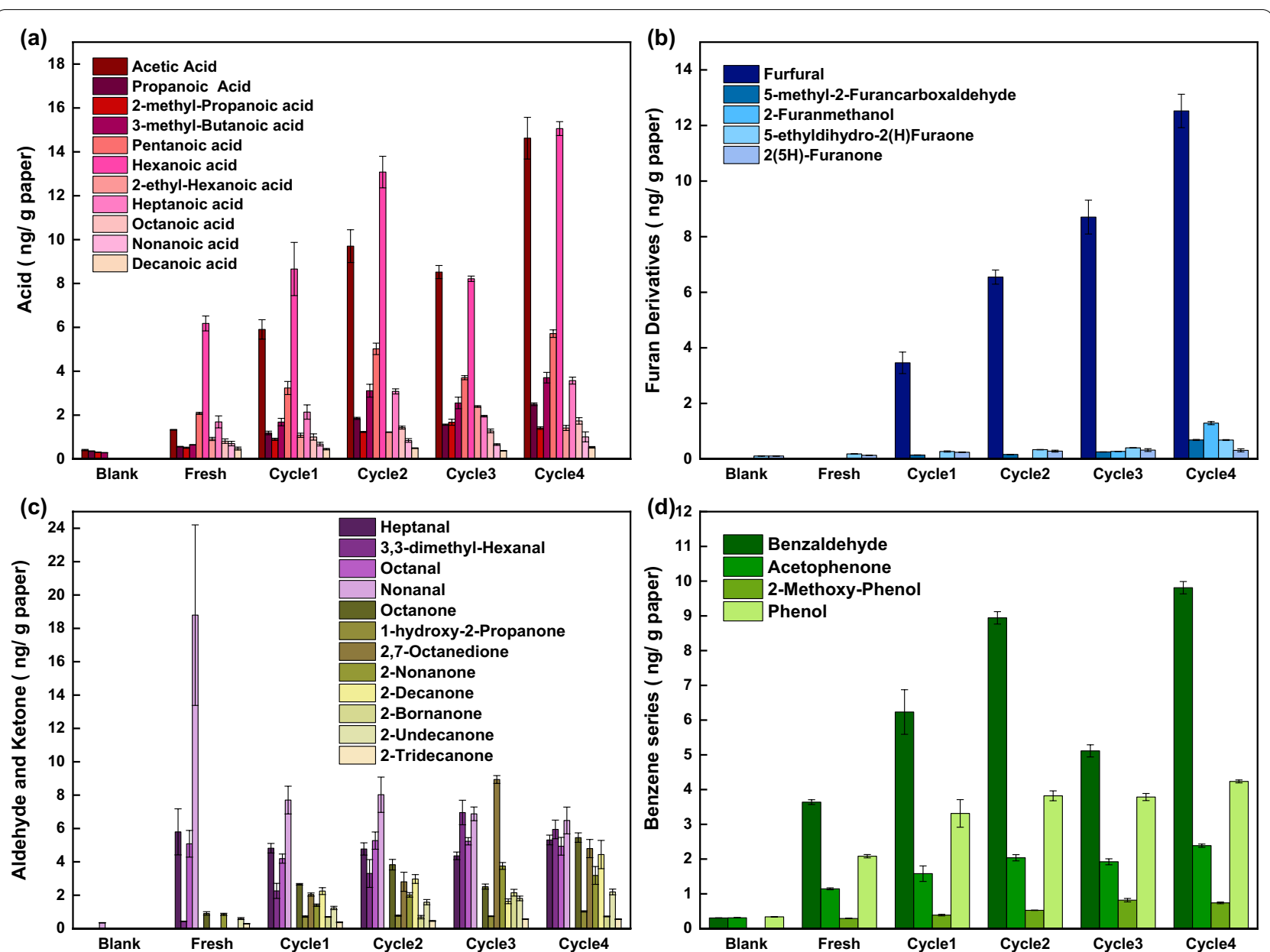

Fig. 5 a The emission rate of aliphatic acid, $\mathbf{b}$ Furfural derivatives, $\mathbf{c}$ aliphatic aldehyde and ketone, $\mathbf{d}$ benzene series in different ageing stage for Bamboo paper

for the first cycle ageing, as the ageing proceeded the concentration of aliphatic aldehyde gradually reduced. However, the content of ketones showed distinct positive correlation with the degradation process. Rich benzene series compounds were found in Rice paper showing in Fig. $6 \mathrm{~d}$. The degradation of its glucoside was monitored by the emission of benzaldehyde and the emission rate is $5.9 \mathrm{ng} / \mathrm{g}$ at ageing cycle 4 . In conclusion, the degradation markers for Rice paper are acetic acid, hexanoic acid, furfural and benzaldehyde.

In addition to the typical handmade paper, the ageing process of mechanical paper was also studied as the control experiment. Since modern and contemporary paper cultural relics were widely made from wood pulp, it is important to get to know the degradation of mechanical wood pulp paper. As shown in Fig. 7a, the amount of acetic acid, hexanoic acid observably increased with degree of ageing process and went up to 12.4 and $13.5 \mathrm{ng} / \mathrm{g}$ at Cycle 4, respectively. Concerning furfural Fig. 7b, it maintained a stable rising tendency as expected. The concentration of furfural is $5.7 \mathrm{ng} / \mathrm{g}$ at cycle 4 . In Fig. 7c, the content of aldehyde $\left(\mathrm{C}_{8}, \mathrm{C}_{9}\right)$ showed an increment in the first cycle then went through a decline in the further ageing stage. The content of ketones showed distinct positive correlation with the degradation process. As shown in Fig. $7 \mathrm{~d}$, various benzene serious compounds were detected and their performance agrees with the degradation process, typically the emission rate of benzaldehyde was $3.6 \mathrm{ng} / \mathrm{g}$ at cycle 4 . Therefore, the degradation markers for wood pulp paper are acetic acid, hexanoic acid, furfural and benzaldehyde.

By comparing the results above, the representative degradation compounds for 3 handmade papers and a mechanical paper were selected. The emission rate of these compounds at ageing Cycle 4 was listed in Table 5. The value provides semi-quantitative comparison for the releasing capacity of VOCs of the paper. The acid releasing capacities are similar to Mulberry, Bamboo, Rice 

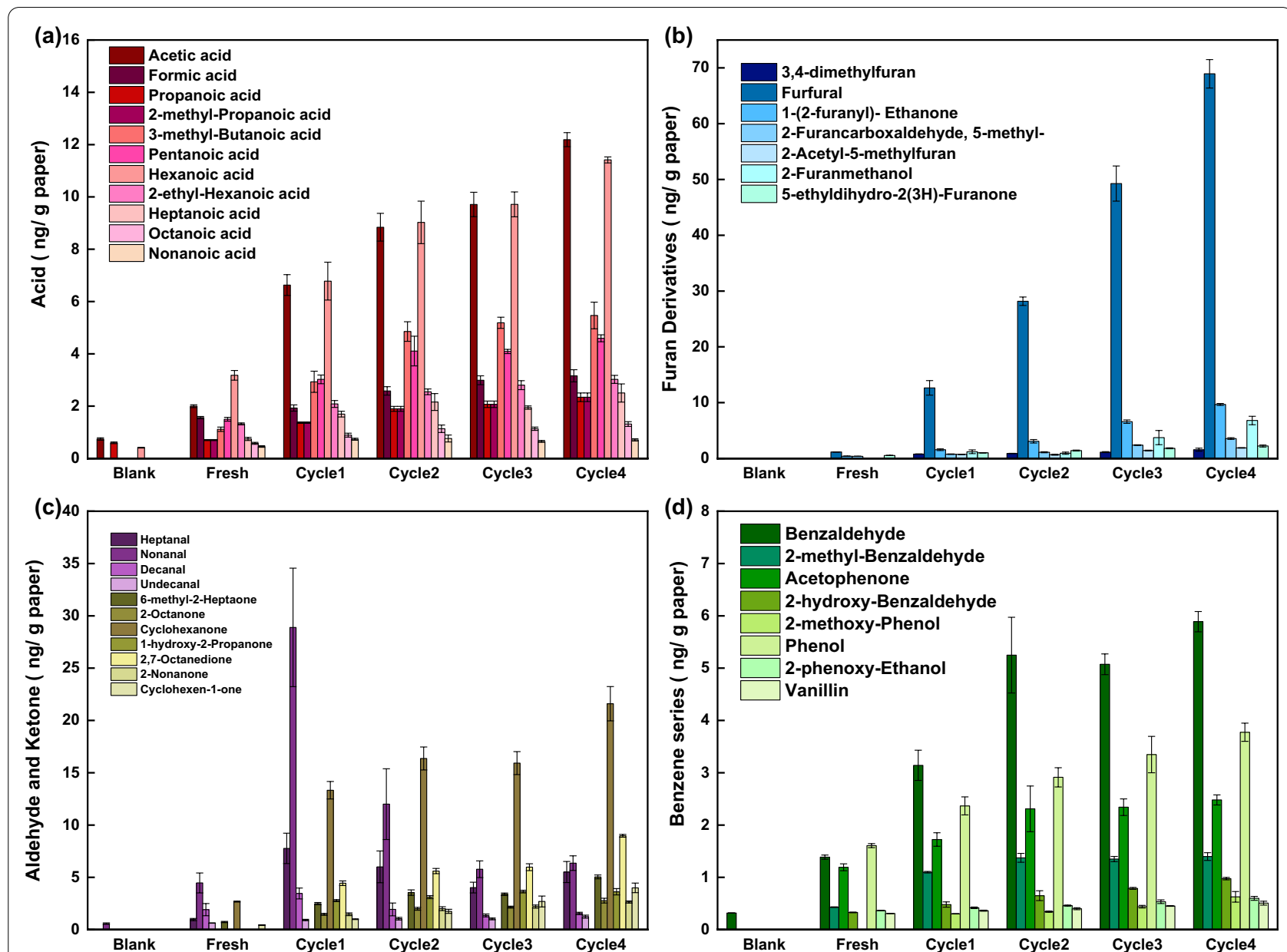

Fig. 6 a The emission rate of aliphatic acid, $\mathbf{b}$ Furfural derivatives, $\mathbf{c}$ aliphatic aldehyde and ketone, $\mathbf{d}$ benzene series in different ageing stage for Rice paper

and Wood pulp paper ranging from 12.1 to $14.6 \mathrm{ng} / \mathrm{g}$ in terms of acetic acid and ranging from 11.4-15.1 ng/g in terms of hexanoic acid, which were generated by the spontaneous reactions with oxygen of aldehyde endgroups. The furfural releasing capacity is the key factor for evaluating the stability of the cellulose and hemicellulose. As shown in Table 5, the stability of paper in terms of furfural releasing capacity is Wood pulp paper $>$ Bamboo paper $>$ Mulberry paper $>$ Rice paper. Benzaldehyde releasing capacity reflects the lignin degradation, which for Bamboo paper is highest $(9.8 \mathrm{ng} / \mathrm{g})$. It might be due to the high concentration of lignin in the Phyllostachys pubescens fibers [23].

\section{Case study}

Jiang Youzhu et al. seven digging mounted painting scroll is a traditional Chinese calligraphy and painting scroll from the Qing Dynasty (C.E 1636-1912) collected by the National Museum of China. The scroll was digging mounted with paper and badly damaged with stains and cracks around the mounting materials. As shown in Fig. 8e, the scroll underwent several historical restorations and treatments. The head margin was repaired at least by three different materials, which are indicated by the number 1, 2, 3 in the Figs. 1 and $8 \mathrm{e}$. Each of the repairing papers were stained with Graff " $\mathrm{C}$ " reagent to assess the presence of color and morphology of fiber. The representative images were shown in Fig. 8a-d. The repairing paper 1,2 and 3 shows the features of bark fiber, since the fibers were wine red and cylindrically straight in shape. Besides, the paper 3 was mixed with bamboo fiber which showed the blue color after dyeing with tapering ends. The original paper of head margin was taken from location 4. As shown in Fig. 8d, the vessel members with pits were unique to bamboo fiber. Therefore, the base paper was bamboo paper and the repairing papers were bark papers. The SEM images of historical paper fibers were also shown in Additional file 1: Fig. S3. Sample 

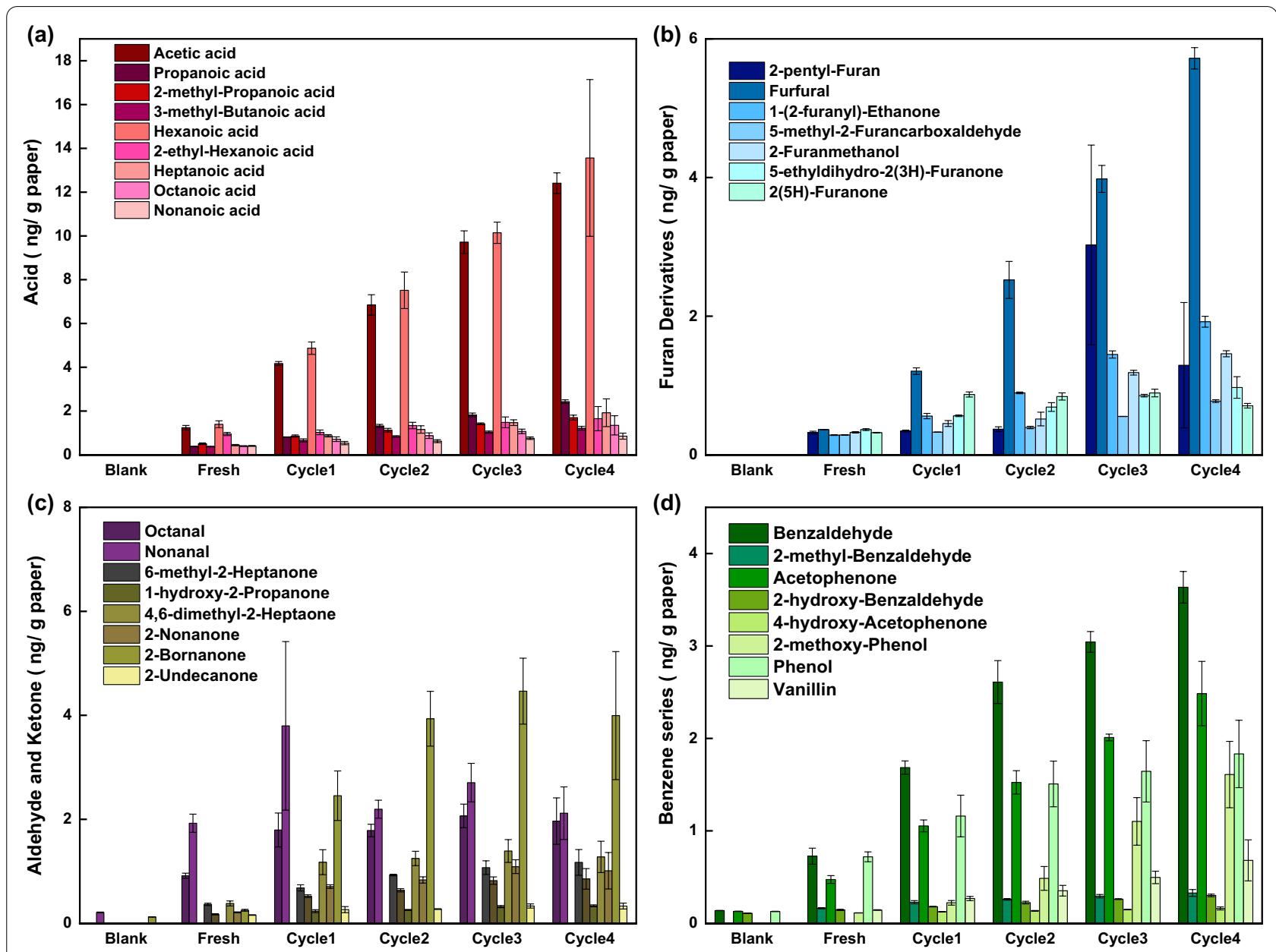

Fig. 7 a The emission rate of aliphatic acid, $\mathbf{b}$ Furfural derivatives, $\mathbf{c}$ aliphatic aldehyde and ketone, $\mathbf{d}$ benzene series in different ageing stage for Wood pulp paper

Table 5 The emission rate of representative compounds in the ageing Cycle 4 of different papers

\begin{tabular}{lllll}
\hline $\mathbf{n g} / \mathbf{g}$ & Acetic acid & Hexanoic acid & Furfural & Benzaldehyde \\
\hline Mulberry & 12.7 & 15.1 & 33.8 & 3.2 \\
Bamboo & 14.6 & 15.1 & 12.5 & 9.8 \\
Rice & 12.1 & 11.4 & 68.9 & 5.9 \\
Wood pulp & 12.4 & 13.5 & 5.7 & 3.6 \\
\hline
\end{tabular}

1-4 was further taken to be evaluated by SPME-GC/MS. Even though the fibers were different among the samples, the TIC of profiles shows the same fingerprint peaks. The representative TIC profile is shown in Fig. 9.

As shown in Fig. 9, 55 compounds were screened out from the head margin paper of Jiang Youzhu et al. seven digging mounted painting scroll. These compounds comprise the aliphatic acid, aldehyde, alkane, benzene series and terpenoid substances (Table 6). The aliphatic acid $\left(\mathrm{C}_{2}-\mathrm{C}_{9}\right)$, aldehyde $\left(\mathrm{C}_{8}-\mathrm{C}_{10}\right)$ and benzene series originated from the degradation of cellulose, hemicellulose, lipid and lignin. Even though, typical degradation marker such as furfural was not found in the TIC mode. However, by carefully checking with the EIC, the furfural was shown at $t_{R}=6.73 \mathrm{~min}$ and the qualitative ion $\mathrm{m} / \mathrm{z}=95$ and $\mathrm{m} / \mathrm{z}=96$ were obtained (Additional file 1: Fig. S5). In addition, Bornanone, endo-Borneol and Isosafrol were detected. These compounds are volatile constituents of the camphor tree and usually the raw material to produce the mothball. The mothball is widely applied in the storage room to keep moths and other insects away. Besides, the camphorwood furniture and storage rack were manipulated in the warehouse of the museum. Therefore, camphor related markers are highly likely originated from the mothball and the camphorwood shelf. Due to the high adsorption ability of the paper, the accumulation of VOCs might almost 

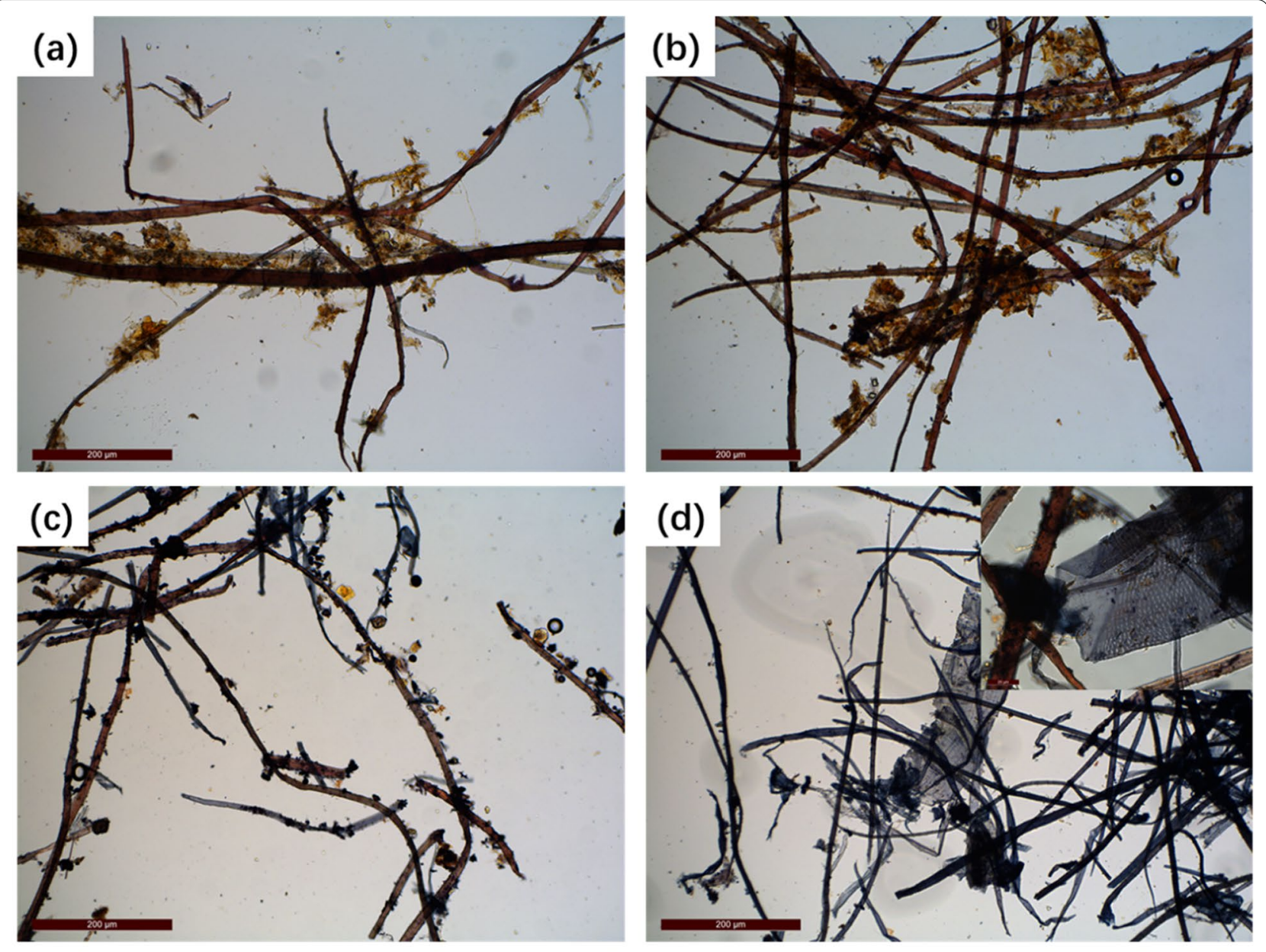

(e)

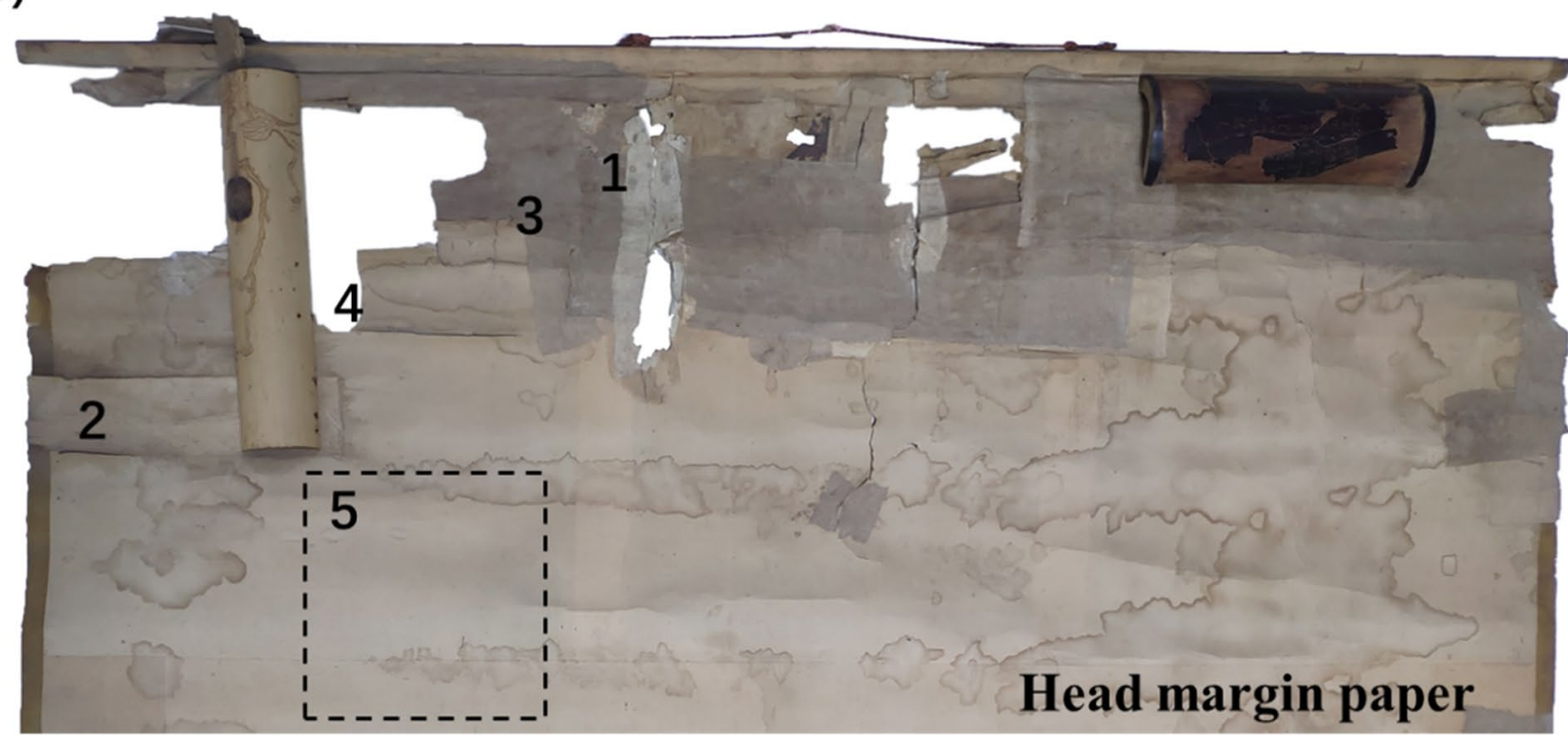

Fig. 8 The optical microscopy image of the paper fibers originated from "Jiang Youzhu et al. seven digging mounted painting scroll" (a), (b), (c), (d) for sampling location 1,2,3,4, respectively, e the photograph of sampling location of Head margin paper 


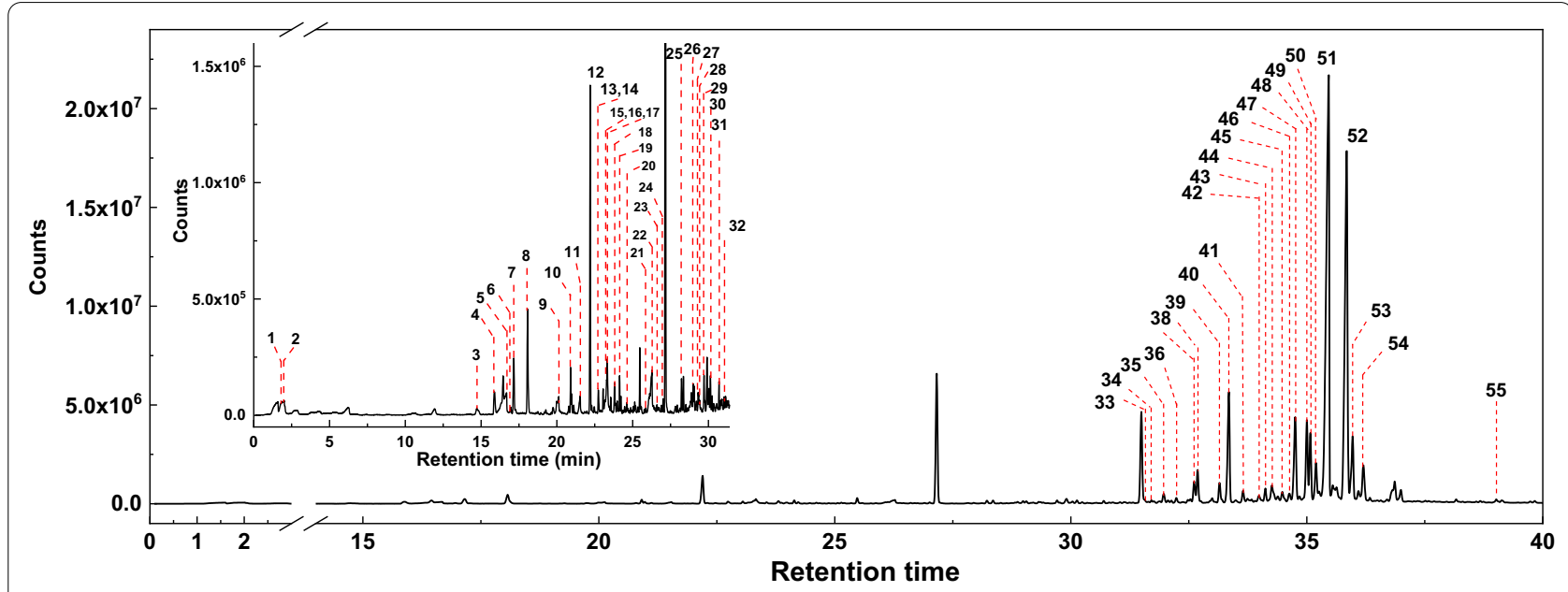

Fig. 9 Total ion current chromatograms obtained from SPME-GC/MS of the margin paper of Jiang Youzhu et al. seven digging mounted painting scroll

Table 6 The assignment of VOCs detected from head margin paper of Jiang Youzhu et al. seven digging mounted painting scroll

\begin{tabular}{|c|c|c|c|c|c|c|c|}
\hline No & $t_{R}$ & Assignment & Score & No & $t_{R}$ & Assignment & Score \\
\hline 1 & 1.87 & Acetic acid & 96 & 29 & 29.71 & Tetradecane & 94 \\
\hline 2 & 2.01 & Methylal & 96 & 30 & 30.13 & Caryophyllene & 83 \\
\hline 3 & 14.70 & Benzaldehyde & 87 & 31 & 30.70 & isoledene & 93 \\
\hline 4 & 15.87 & Phenol & 96 & 32 & 31.05 & Humulene & 79 \\
\hline 5 & 16.68 & Hexanoic acid & 95 & 33 & 31.57 & 1-Dodecanol & 95 \\
\hline 6 & 16.96 & Octanal & 84 & 34 & 31.71 & a-Curcumene & 86 \\
\hline 7 & 17.16 & Benzene, 1,3-dichloro- & 98 & 35 & 31.97 & $(+)$-Valencene & 97 \\
\hline 8 & 18.07 & 1-Hexanol, 2-ethyl- & 98 & 36 & 32.23 & Pentadecane & 96 \\
\hline 9 & 20.13 & Heptanoic acid & 89 & 37 & 32.61 & 8-Cadinene & 92 \\
\hline 10 & 20.91 & Nonanal & 99 & 38 & 32.69 & trans-Calamenene & 94 \\
\hline 11 & 21.54 & Hexanoic acid, 2-ethyl- & 96 & 39 & 33.15 & a-Calacorene & 93 \\
\hline 12 & 22.20 & (+)-2-Bornanone & 99 & 40 & 33.35 & Elemol & 98 \\
\hline 13 & 22.73 & Benzaldehyde, 3-ethyl- & 98 & 41 & 33.65 & $\beta$-Calacorene & 88 \\
\hline 14 & 22.76 & endo-Borneol & 82 & 42 & 33.98 & Caryophyllenyl alcohol & 86 \\
\hline 15 & 23.28 & Benzaldehyde, 4-ethyl- & 85 & 43 & 34.12 & Caryophyllene oxide & 94 \\
\hline 16 & 23.32 & Octanoic acid & 84 & 44 & 34.25 & Gleenol & 86 \\
\hline 17 & 23.34 & Naphthalene & 90 & 45 & 34.48 & Guaiol & 92 \\
\hline 18 & 23.81 & a-Terpineol & 85 & 46 & 34.63 & Hexadecane & 95 \\
\hline 19 & 24.22 & Decanal & 93 & 47 & 34.75 & Cedrol & 97 \\
\hline 20 & 24.61 & 1,2-Benzisothiazole & 88 & 48 & 35.00 & a-Eudesmol & 90 \\
\hline 21 & 25.77 & Ethanone, 1-(4-ethylphenyl)- & 86 & 49 & 35.07 & $\gamma$-Eudesmol & 97 \\
\hline 22 & 26.27 & Nonanoic acid & 93 & 50 & 35.19 & Di-epi-1,10-cubenol & 97 \\
\hline 23 & 26.60 & 1,3-Benzodioxole, 5-(1-propenyl)- & 88 & 51 & 35.46 & Agarospirol & 95 \\
\hline 24 & 27.00 & Tridecane & 88 & 52 & 35.84 & $(+)$-Valerianol & 96 \\
\hline 25 & 28.23 & a.-Cubebene & 93 & 53 & 35.97 & 7-epi-a-Eudesmol & 96 \\
\hline 26 & 28.99 & Copanen & 87 & 54 & 36.19 & Cadalene & 97 \\
\hline 27 & 29.32 & $(+)$-Calarene & 90 & 55 & 39.01 & Octadecane & 92 \\
\hline 28 & 29.42 & p-Anisaldehyde, 2-hydroxy- & 88 & & & & \\
\hline
\end{tabular}


come from the environment. However, it is very hard to evaluate how long paper can hold onto past absorbed VOCs before releasing them. It is also worth noticing that at 27 to $39 \mathrm{~min}$, in other words, between the n-alkane of $\mathrm{C}_{13}$ and $\mathrm{C}_{18}$, abundant terpenoid substances are eluted, like $\alpha$-cubebene, copanen, $(+)$-calarene, 2-hydroxy-p-anisaldehyde, caryophyllene, caryophyllenyl alcohol, agarospirol and so on. Among them, the agarospirol is a typical plant marker of the agarwood, and the other terpenoids were reported to be found in the VOCs constituents of the agarwood as well depending on its place of origin [39]. The Vietnam agarwood were obtained and the SPME-GC-MS result was collected to ensure the existence of agarospirol as shown in Additional file 1: Fig. S6. This result hints that the scroll somehow had a relationship with the agalwood. It might be from the raw material of paper or be contaminated from the storage environment. However, it needs further studies to clarify. In order to evaluate the releasing capacity of the degradation marker molecule, historical paper was processed with the ageing program the same as reference paper. At ageing cycle 4 , compared to the fresh reference paper sample, the historical paper releases a large amount of degradation products. As shown in Table 7, at ageing cycle 4, the acid releasing capacities is $32.9 \mathrm{ng} / \mathrm{g}$ in terms of acetic acid and $43.7 \mathrm{ng} / \mathrm{g}$ in terms of hexanoic acid, which are around 2 and 3 times of the reference bamboo paper. The releasing capacity of furfural and benzaldehyde is $162.8 \mathrm{ng} / \mathrm{g}$ and $19.2 \mathrm{ng} / \mathrm{g}$, which is 13 times and 2 times of the reference bamboo paper, respectively. Chain scission of cellulose, hemicellulose and lignin is a key step of paper degradation, which leads to producing various monosaccharide and benzene series [2]. These small molecule compounds are precursors to produce the VOCs, such as furan derives, short chain aliphatic acids. Since the historical paper experienced more than 100-year natural ageing, a large number of small molecules were accumulated, which are easier to be given off as VOCs products during the artificial ageing process. Meanwhile, consideration of brittle paper with low DP (degree of polymerization), more end-groups exposure and lead to the faster monomer generation. Therefore, due to its high releasing capacity of the degradation

Table 7 The emission rate of representative compounds in the ageing Cycle 4 of historical paper

\begin{tabular}{lllll}
\hline $\mathbf{n g} / \mathbf{g}$ & Acetic acid & $\begin{array}{l}\text { Hexanoic } \\
\text { acid }\end{array}$ & Furfural & Benzaldehyde \\
\hline $\begin{array}{l}\text { Historical } \\
\text { paper }\end{array}$ & 32.9 & 43.7 & 162.8 & 19.2 \\
\hline
\end{tabular}

markers, the historical paper is under a serious degradation situation.

\section{Conclusions}

Solid phase microextraction combined with gas chromatography-mass spectrometry (SPME-GC/MS) has been applied and proved to be useful to evaluate volatile organic components (VOCs) emitted from the Chinese traditional handmade papers. The artificial ageing processes were applied to 3 different handmade papers in addition to a mechanical paper as the control experiments. 87 compounds were identified using the Total Ion Current and attributed to originate from cellulose, hemicellulose, lignin, lipid, wax and plant markers. Compounds with 5 different functional groups (aliphatic acid, aldehyde, ketone, furan derivatives and benzene series) were evaluated semi-quantitatively during the aging process. It was found that the aldehydes are not accumulated as aging products of paper, which has not been demonstrated before. Further, VOCs were evaluated in historical paper from a traditional Chinese calligraphic and painting scroll, which was collected by the National Museum of China. A large number of terpenoids showed that the VOCs emitted from the paper not only originated from the paper itself but also could be generated from the substance absorbed on paper, which gives information about the historical storage environment. The artificial ageing process provided the releasing capacity of the degradation markers, which quantitatively illustrate the severe condition of the historical paper. Therefore, SPME-GC/ MS provided a powerful tool for study of the VOCs of paper-based heritages and allowed the assessment of the degradation products, which is critical for the paper ageing evaluation and of great significance for contemporary conservation.

\section{Supplementary Information}

The online version contains supplementary material available at https://doi. org/10.1186/s40494-021-00626-w.

Additional file 1. Additional figures and tables.

Additional file 2. Original data of semi-quantifying VOCs from artificial ageing paper.

\section{Acknowledgements}

The reference paper was kindly provided by the Conservator Xiaofang Lv and Jianhui Liu.The manuscript was kindly improved by Yitan Lee and Jiamei Zeng on the language aspect.

\section{Authors' contributions}

L. Ding designed experiments, analyzed experimental data and was a major contributor in writing the manuscript. Q. Yang analyzed paper fibers via scanning electron microscope. Jh. Liu provided the reference paper samples. Zh. Lee provided the historical paper samples. All authors read and approved the final manuscript. 


\section{Funding}

This research is financially supported by the scientific foundation of National Museum of China. Grant No. GBKX2019Y01.

\section{Availability of data and materials}

Not applicable.

\section{Declarations}

\section{Competing interests}

No potential conflict of interest was reported by the author(s).

Received: 25 August 2021 Accepted: 1 November 2021

Published online: 17 November 2021

\section{References}

1. M. Strlič, J. Kolar, Ageing and stabilisation of paper, National and university library Ljubljana, 2005.

2. Daniels VD. The chemistry of paper conservation. Chem Soc Rev. 1996:25:179. https://doi.org/10.1039/CS9962500179.

3. Zięba-Palus J, Wesełucha-Birczyńska A, Trzcińska B, Kowalski R, Moskal P. Analysis of degraded papers by infrared and Raman spectroscopy for forensic purposes. J Mol Struct. 2017;1140:154-62. https://doi.org/10. 1016/j.molstruc.2016.12.012

4. Kher A, Mulholland M, Reedy B, Maynard P. Classification of document papers by infrared spectroscopy and multivariate statistical techniques. Appl Spectr. 2001;55:1192-8. https://doi.org/10.1366/0003702011953199.

5. Łojewska J, Miśkowiec P, Łojewski T, Proniewicz LM. Cellulose oxidative and hydrolytic degradation: In situ FTIR approach. Polym Degrad Stabil. 2005;88:512-20. https://doi.org/10.1016/j.polymdegradstab.2004.12.012.

6. Malachowska E, Dubowik M, Boruszewski P, Lojewska J, Przybysz P. Influence of lignin content in cellulose pulp on paper durability. Sci Rep. 2020. https://doi.org/10.1038/s41598-020-77101-2.

7. Keheyan Y. PY/GC/MS analyses of historical papers. BioResources. 2008:3:829-37.

8. Keheyan Y, Eliazyan G, Engel P, Rittmeier B. Py/GC/MS characterisation of naturally and artificially aged inks and papers. J Analy Appl Pyroly. 2009;86:192-9. https://doi.org/10.1016/j.jaap.2009.06.004.

9. Han B, Vial J, Sakamoto S, Sablier M. Identification of traditional East Asian handmade papers through the multivariate data analysis of pyrolysis-GC/ MS data. Analyst. 2019;144:1230-44. https://doi.org/10.1039/c8an01898g.

10. Long-Kun YX, Zhipei Y, Zhouling T, Ming Z, Shanshan R. Study on the Effect of Furfural on Durability of Paper Literature. Study Nat Cult Heritage. 2019:4:111-4.

11. Dupont AL, Tetreault J. Cellulose Degradation in an Acetic Acid Environment. Stud Conserv. 2013:45:201-10. https://doi.org/10.1179/sic.2000 45.3.201.

12. Strlič M, Kralj Cigić I, Možir A, de Bruin G, Kolar J, Cassar M. The effect of volatile organic compounds and hypoxia on paper degradation. Polym Degrad Stabil. 2011;96:608-15. https://doi.org/10.1016/j.polymdegra dstab.2010.12.017.

13. Jablonsky M, Hrobonova K, Katuscak S, Lehotay J, Botkova M. Formation of acetic and formic acid in unmodified and modified papers during accelarated ageing. Cell Chem Technol. 2012;46:331.

14. Strlic M, Cigic IK, Kolar J, De Bruin G, Pihlar B. Non-destructive evaluation of historical paper based on $\mathrm{pH}$ estimation from VOC emissions. Sensors (Basel). 2007;7:3136-45. https://doi.org/10.3390/s7123136.

15. Strlic M, Thomas J, Trafela T, CseFalvayova L, Kralj Cigic I, Kolar J, Cassar M. Material degradomics: on the smell of old books. Analy Chem. 2009;81:8617-22. https://doi.org/10.1021/ac9016049.

16. Curran K, Underhill M, Grau-Bove J, Fearn T, Gibson LT, Strlic M. Classifying degraded modern polymeric museum artefacts by their smell. Angew Chem Int Edit. 2018;57:7336-40. https://doi.org/10.1002/anie.201712278.

17. Bembibre C, Strlič M. Smell of heritage: a framework for the identification, analysis and archival of historic odours. Herit Sci. 2017;5:2. https://doi.org/ 10.1186/s40494-016-0114-1.
18. Lattuati-Derieux A, Thao S, Langlois J, Regert M. First results on headspace-solid phase microextraction-gas chromatography/mass spectrometry of volatile organic compounds emitted by wax objects in museums. J Chromatogr A. 2008;1187:239-49. https://doi.org/10.1016/j. chroma.2008.02.015.

19. SawoszczukT, Sygula-Cholewinska J, del Hoyo-Melendez JM. Application of solid-phase microextraction with gas chromatography and mass spectrometry for the early detection of active moulds on historical woollen objects. J Sep Sci. 2017;40:858-68. https://doi.org/10.1002/jssc.20160 1018.

20. Adamová T, Hradecký J, Pánek M. Volatile organic compounds (VOCs) from wood and wood-based panels: methods for evaluation. Potent Health Risks Mitig Polym. 2020;12:2289. https://doi.org/10.3390/polym 12102289.

21. La Nasa J, Modugno F, Colombini MP, Degano I. Validation study of selected ion flow tube-mass spectrometry (SIFT-MS) in heritage science: characterization of natural and synthetic paint varnishes by portable mass spectrometry. J Am Soc Mass Spectrom. 2019;30:2250-8. https:// doi.org/10.1007/s13361-019-02305-4.

22. La Nasa J, Mattonai M, Modugno F, Degano I, Ribechini E. Comics'VOCabulary: Study of the ageing of comic books in archival bags through VOCs profiling. Polym Degrad Stabil. 2019;161:39-49. https://doi.org/10. 1016/j.polymdegradstab.2019.01.001.

23. Lattuati-Derieux A, Bonnassies-Termes S, Lavédrine B. Use of headspacesolid-phase microextraction/gas chromatography/mass spectrometry. J Cult Herit. 2006;7:123-33. https://doi.org/10.1016/j.culher.2006.02.004.

24. Gutteridge JMC. Lipid peroxidation and antioxidants as biomarkers of tissue damage. Clin Chem. 1995;41:1819-28. https://doi.org/10.1093/clinc hem/41.12.1819.

25. Gaspar EM, Santana JC, Lopes JF, Diniz MB. Volatile organic compounds in paper-an approach for identification of markers in aged books. Anal Bioanal Chem. 2010;397:369-80. https://doi.org/10.1007/s00216-010-3520-3.

26. Lattuati-Derieux A, Bonnassies-Termes S, Lavedrine B. Identification of volatile organic compounds emitted by a naturally aged book using solid-phase microextraction/gas chromatography/mass spectrometry. J Chromatogr A. 2004;1026:9-18. https://doi.org/10.1016/j.chroma.2003.11. 069.

27. Battistel D, Padovani I, Dallo F, Barbante C, Zendri E, Balliana E. Evaluation of the volatile organic compound emissions in modern and naturally aged Japanese paper. J Cult Herit. 2018;33:18-29. https://doi.org/10. 1016/j.culher.2018.03.013.

28. Cerkowniak M, Bogus MI, Wloka E, Stepnowski P, Golebiowski M. Application of headspace solid-phase microextraction followed by gas chromatography coupled with mass spectrometry to determine esters of carboxylic acids and other volatile compounds in Dermestes maculatus and Dermestes ater lipids. Biomed Chromatogr. 2018. https://doi.org/10. 1002/Bmc.4051.

29. H. XiFan (黄锡蕃), Mingzhong Shuhualu (闽中书画录), Qing Dynasty.

30. Clark AJ, Calvillo JL, Roosa MS, Green DB, Ganske JA. Degradation product emission from historic and modern books by headspace SPME/GC-MS: evaluation of lipid oxidation and cellulose hydrolysis. Anal Bioanal Chem. 2011;399:3589-600. https://doi.org/10.1007/s00216-011-4680-5.

31. Lattuati-Derieux A, Ramalho O, Egasse C, Thao-Heu S, Dupont A-L. Evaluation of solid-phase microextraction on-fiber derivatization for the analysis of paper degradation compounds, E-Preservation. Science. 2015;12:38-49.

32. Ouyang G, Pawliszyn J. A critical review in calibration methods for solidphase microextraction. Anal Chim Acta. 2008;627:184-97. https://doi.org/ 10.1016/j.aca.2008.08.015.

33. Ouyang G, Chen Y, Setkova L, Pawliszyn J. Calibration of solid-phase micro-extraction for quantitative analysis by gas chromatography. J Chromatogr A. 2005;1097:9-16. https://doi.org/10.1016/j.chroma.2005.08. 017.

34. Pouriman M, Caparanga AR, Ebrahimi M, Dahresobh A. Characterization of Untreated and Alkaline-Treated Salago Fibers (Genus Wikstroemia spp.). J Nat Fibers. 2017;15:296-307. https://doi.org/10.1080/15440478.2017. 1329105. 
35. Ramkumar R, Saravanan P. Characterization of the cellulose fibers extracted from the bark of Piliostigma Racemosa. J Nat Fibers. 2021 https://doi.org/10.1080/15440478.2021.1875356.

36. Komuraiah A, Kumar NS, Prasad BD. Chemical composition of natural fibers and its influence on their mechanical properties. Mech Compos Mater. 2014;50:359-76.

37. Verma RS, Padalia RC, Singh VR, Goswami P, Chauhan A, Bhukya B. Natural benzaldehyde from Prunus persica (L.) Batsch. Int J Food Propert. 2017. https://doi.org/10.1080/10942912.2017.1338728.

38. Haisman D, Knight D. The enzymic hydrolysis of amygdalin. Biochem J. 1967;103:528. https://doi.org/10.1042/bj1030528.
39. Tsan PLJP, Mohamed R. Gas chromatography-mass spectrometry analysis of agarwood extracts from mature and juvenile Aquilaria malaccensis. Int J Agric Biol. 2014;16:1.

\section{Publisher's Note}

Springer Nature remains neutral with regard to jurisdictional claims in published maps and institutional affiliations.

\section{Submit your manuscript to a SpringerOpen ${ }^{\circ}$ journal and benefit from:}

- Convenient online submission

- Rigorous peer review

- Open access: articles freely available online

- High visibility within the field

- Retaining the copyright to your article

Submit your next manuscript at springeropen.com 